\title{
In vitro antioxidant activity of the ethanolic extract from fruit, stem, and leaf of Solanum torvum
}

\author{
Abdulaziz R. Abdulkadir ${ }^{\mathrm{a}}$, Nashriyah Mat ${ }^{\mathrm{a}}$, Md M. Hasan ${ }^{\mathrm{b}}$, Md S. Jahan ${ }^{\mathrm{a}, *}$ \\ a Faculty of Bioresources and Food Industry, Sultan Zainal Abidin University, Tembila Campus, \\ 22200 Besut, Terengganu, Malaysia \\ b Department of Agricultural Botany, Faculty of Agriculture. Patuakhali Science and Technology University, \\ Dumki, Patuakhali, 8602 Bangladesh
}

*Corresponding author, e-mail: sarwarjahan@unisza.edu.my

Received 13 Jan 2016

Accepted 21 Jun 2016

\begin{abstract}
Secondary metabolites in the Solanaceae group of plants influence human health. Hence fruits and beverages from Solanum torvum are becoming essential not only for their nutritional value but also for medicinal benefits. This study evaluates the antioxidant activity of the extract of fruit, leaf, and stem of $S$. torvum. Total phenolic and flavonoid contents were evaluated using the Folin-Ciocalteu method and $\mathrm{AlCl}_{3}$ test, respectively. Antioxidant activities were assessed by DPPH radical scavenging and the ferric-reducing antioxidant power assays. The results showed that stem extracts accumulated significantly higher phenolic content and higher reducing ability than the extracts of fruit and leaf. Extracts of leaves contained significantly higher flavonoid content and higher antioxidant capacity towards DPPH than that of in extract of fruit and stem. This result suggests that extracts of stems exhibited a good reducing ability, whereas the extract of leaves displayed an excellent DPPH free radical scavenging ability.
\end{abstract}

KEYWORDS: DPPH, flavonoid content, Folin-Ciocalteu, medicinal benefit, phenolic content

\section{INTRODUCTION}

Solanum torvum is a plant of the family of the Solanaceae, which contains a number of important medicinal plants such as $S$. hispidum, $S$. tuberosum, S. abutiloides, $S$. torvum, and Capsicum annuum. It grows in different climatic regions, e.g., West Indies, Thailand, Malaysia, Myanmar, India, China and in some parts of tropical America. It is naturally found in South and South-East Asia ${ }^{1}$. The fruits of this plant are edible. However, a Cameroonian folk medicine utilizes the fruit and leaves as a source of medicine ${ }^{2}$. It is also used to treat fever, tooth decay, wounds ${ }^{3}$, colds and coughs, cracked foot, reduce body heat, and microbial diseases ${ }^{1}$.

The ripened fruits of $S$. torvum contain steroidal glycosides ${ }^{4}$, hydrocarbons and steroids ${ }^{5}$, antioxidant proteins ${ }^{6}$ used as traditional medicine. Phytochemical studies have shown that fruits contain alkaloids, glycosides, flavonoids, tannins, and saponins that have adequate pharmacological properties $^{1}$. Several reports confirmed that the plant has many pharmacological properties such as analgesic and antiinflammatory ${ }^{3}$, anti-microbial ${ }^{7,8}$, anti-ulcerogenic activity ${ }^{9}$, antihypertensive ${ }^{10}$, antioxidant activity ${ }^{11,12}$. The root and the stem of $S$. torvum showed an antitumour, antiinflammatory, antiviral, and antibacterial activity ${ }^{1}$.

Recently, oxidative related problems are seriously increased with the advent of many possible ways to generate oxidative diseases via free radicals. Sources of free radicals include UV light, pollutants, ionizing radiation, industrial waste, cigarette smoke, certain organic solvents, and some cellular activities ${ }^{13}$. Free radicals are extremely reactive compounds formed when oxygen reacts with certain molecules. However, they became stable compounds in the presence of other molecules ${ }^{14}$. This necessitates many scientists to use herbs and spices as antioxidant.

Recently, many oxidative related problems and infectious diseases were reported to be controlled using herbs and spices in food ${ }^{14}$. Thus herbs are important in managing human diseases due to the content of active compounds. Hence this study evaluates the antioxidant activity in fruit, leaf, and stem of $S$. torvum, an indigenous plant in peninsular Malaysia. 


\section{MATERIALS AND METHODS}

\section{Chemicals}

Dimethyl sulfoxide (DMSO), 2,2-diphenyl-1-picrylhydrazyl (DPPH), 2,4,6-tripyridyl-s-triazine (TPTZ), Folin-Ciocalteu, quercetin, $\mathrm{FeCl}_{3}$, acetate buffer ( $\mathrm{pH}$ 3.6), ethanol, methanol, and $\mathrm{Na}_{2} \mathrm{CO}_{3}$ were used in this experiment. Antioxidant activity was assessed using DPPH scavenging activity and ferricreducing antioxidant power assays.

\section{Plant materials}

The samples were collected from a university farm at Tembila Campus, Sultan Zainal Abidin University (UniSZA). The samples were then washed with running tap water and then separated into fruit, stem, and leaves before drying them in an oven. The Faculty of Bioresources and Food Industry, UniSZA, Tembila campus Besut, Terengganu, Malaysia, authenticated the plant.

\section{Extract preparation}

The leaf, stem, and fruit (pod) samples were washed properly and separated into stem (stalk), bark, stem with bark, pod, and seed followed by subsequent drying at $40-43^{\circ} \mathrm{C}$ for 3 days. The dried samples were extracted with $100 \%$ methanol. The crude extracts were collected at least three times and were filtered through Whatman number 1 filter paper and then concentrated on a rotary evaporator (Buchi, Flavil, Switzerland) at $45^{\circ} \mathrm{C}$, dried and kept at $4{ }^{\circ} \mathrm{C}$ until used for the assay. The sample and solvent mass ratio were 1:2 during extraction. The extracts were dissolved in DMSO, methanol, and/or diluted with sterile water to obtain the final concentration as per requirement ${ }^{15}$.

\section{Total phenolic content (TFC) assay}

The Folin-Ciocalteu (F-C) method of assay is the simplest method available for the measurement of phenolic content in the products. The improved method using F-C reagent can be performed by two principal procedures for the measurement of polyphenolic content, i.e., as dual reagent ${ }^{16}$ and as single reagent ${ }^{17}$. The single reagent has been used for phenolic antioxidants from fruits ${ }^{17}$. A total phenolic content of the extract was determined according to the previous method ${ }^{18,19}$ with some modification. In the experiment, $250 \mu \mathrm{l}$ of extract diluted in methanol was placed in a test tube and later mixed with $1.25 \mathrm{ml}$ of F-C reagent diluted 1:9 with distilled water. Then, it was incubated for $10 \mathrm{~min}$, after which $1 \mathrm{ml}$ of $8 \% \mathrm{Na}_{2} \mathrm{CO}_{3}$ solution was added, followed by a second incubation for $30 \mathrm{~min}$ in dark prior to measuring at $650 \mathrm{~nm}$ in a spectrophotometer. Gallic acid solution was used as a standard in a concentration range from 0.5$25 \mu \mathrm{g} / \mathrm{ml}$. Total phenolic content was stated as $\mathrm{mg}$ gallic acid equivalents (GAE)/g of samples. Three replicates were maintained.

\section{Total flavonoid content (TFC) assay}

The total flavonoid content was determined using a modified method ${ }^{20,21}$. A $0.32 \mathrm{mg} / \mathrm{ml}$ methanol solution of quercetin was used for this assay and was further diluted, and read at $415 \mathrm{~nm}$ into different concentrations of $250,125,62.5,31.25,15.63$, and $7.81(\mu \mathrm{g} / \mathrm{ml})$. A calibration curve was prepared from the above dilutions measuring the absorbance at $415 \mathrm{~nm}$ with a spectrophotometer. Concisely, $0.5 \mathrm{ml}$ of each extract was mixed with $1.5 \mathrm{ml}$ of methanol, $0.1 \mathrm{ml}$ of $10 \% \mathrm{AlCl}_{3}, 0.1 \mathrm{ml}$ of $1 \mathrm{M}$ potassium acetate and $2.8 \mathrm{ml}$ of distilled water. Three replicates were prepared.

\section{2,2-diphenyl-1-picrylhydrazyl (DPPH) assay}

Antioxidant activity of the extracts from different parts of $S$. torvum on DPPH was assessed based on the modified method ${ }^{22,23}$. For this assay, $60 \mu \mathrm{l}$ of extract diluted in DMSO was mixed with $200 \mu$ l of DPPH in methanol $(0.1 \mathrm{mM})$, to form a total volume of $260 \mu \mathrm{l}$ per well. The mixture in the tube was shaken vigorously and kept in the dark for a maximum of 30 min for the reaction between DPPH and the antioxidant compounds to develop. The colour of the solution changed from dark violet to light yellow. Then the absorbance of the solution was recorded at $517 \mathrm{~nm}$ with UV-Vis spectrophotometer (Shimadzu). Corresponding blank samples were prepared and L-ascorbic acid (1-100 $\mu \mathrm{g} / \mathrm{ml}$ ) was used as a reference standard. A standard quercetin solution dissolved in methanol was run together with a blank solution containing methanol only. The radical scavenging property of the fruits was determined by calculating the IC50 (the concentration reducing DPPH absorbance by $50 \%$ ).

The DPPH scavenging effect was calculated as: inhibition $=\left(A_{0}-A_{1}\right) / A_{0}$, where $A_{0}$ is the absorbance of the control reaction and $A_{1}$ is the absorbance in the presence of the sample. Three replicates were prepared.

\section{Ferric-reducing antioxidant power assay}

The ferric-reducing antioxidant power (FRAP) assay was carried out as the described method with modification $^{24}$. The FRAP reagent was prepared using 
Table 1 Linear equations and their $R^{2}$ values obtained from the standard calibration curves.

\begin{tabular}{llc}
\hline Assays & \multicolumn{1}{c}{ Calibrations curve } & $R^{2}$ \\
\hline TFC & $Y=0.0025 X+0.0708$ & 0.9986 \\
TPC & $Y=0.0088 X+0.0932$ & 0.9991 \\
FRAP & $Y=0.0005 X+1.6929$ & 0.9996 \\
\hline
\end{tabular}

$10 \mathrm{mM}$ TPTZ (2, 4, 6-tripyridyl-s-triazine) solution in $40 \mathrm{mM} \mathrm{HCl}, 20 \mathrm{mM} \mathrm{FeCl}_{3}$ aqueous solution and acetate buffer $(\mathrm{pH} \mathrm{3.6)}$ in the ratio 1:1:10 (v/v), respectively. A fresh FRAP reagent was prepared and heated at $37^{\circ} \mathrm{C}$ in a water bath for $30 \mathrm{~min}$ before use. A $50 \mu l$ of sample was added to $1.5 \mathrm{ml}$ FRAP reagent. After $30 \mathrm{~min}$ of incubation, the absorbance of the reaction mixture was measured in a spectrophotometer at $593 \mathrm{~nm}$. A $2000 \mu \mathrm{M}$ iron(II) sulphate solution was used as a standard and subsequently diluted to $1000,500,250,125$, 62.5 , and $31.25 \mu \mathrm{M}$. The results are expressed as $\mathrm{mM} \mathrm{Fe}(\mathrm{II}) / \mathrm{g}$ dry weight of plant material. Three replications were prepared and the mean values were calculated.

\section{Statistical analysis}

Each assay was subjected to one-way ANOVA using Statistical Package for Social Sciences (SPSS). A significance level of $0.05 \%$ was used to test differences between the samples used.

\section{RESULTS}

\section{Total phenolic and total flavonoid contents}

Total phenolic contents (TPC) and total flavonoid contents (TFC) were calculated from the extracts of fruit, stem, and leaf using the standard curve of gallic acid and quercetin solution, respectively (Table 1). The data were interpreted regarding GAE (gallic acid equivalents) and QAE (quercetin equivalents) of the extract, respectively. In Table 1 , $Y$ represents the average absorbance of the sample and $X$ stands for the amount of gallic acid or quercetin acid in $\mu \mathrm{g} / \mathrm{ml}$.

The results of phenolic content of these samples showed a significant difference $(p<0.05)$. The extracts of the stem of $S$. torvum showed the highest level of phenolic content of $43.92 \pm 0.17$ (mg GAE/g) which was significantly higher than that of the phenolic content of the leaf $(37.48 \pm 0.41 \mathrm{mg}$ $\mathrm{GAE} / \mathrm{g}$, Table 2). In addition, the phenolic content of the leaf was significantly higher than that of the fruit $(16.15 \pm 0.23 \mathrm{mg} \mathrm{GAE} / \mathrm{g}$, Table 2$)$. The flavonoid content of $40.6 \pm 1.9$ (mg QAE/g) in leaf
Table 2 Estimation of the total phenolic content (TPC; mg $\mathrm{GAE} / \mathrm{g}$ ) and the total flavonoid content (TFC; mg GAE/g) in the different parts of $S$. torvum plants.

\begin{tabular}{lcc}
\hline Sample & TPC (mg GAE/g) & TFC (mg QAE/g) \\
\hline Fruit & $16.15 \pm 0.23^{\mathrm{c}}$ & $1.41 \pm 0.61^{\mathrm{c}}$ \\
Stem & $43.92 \pm 0.17^{\mathrm{a}}$ & $16.21 \pm 0.46^{\mathrm{b}}$ \\
Leaf & $37.48 \pm 0.41^{\mathrm{b}}$ & $40.6 \pm 1.9^{\mathrm{a}}$ \\
\hline
\end{tabular}

Table 3 DPPH percentage inhibition in the different parts from $S$. torvum.

\begin{tabular}{lc}
\hline Sample & inhibition (\%) \\
\hline Fruit & $33.0 \pm 1.1^{\mathrm{c}}$ \\
Stem & $56.3 \pm 0.9^{\mathrm{b}}$ \\
Leaf & $78.7 \pm 1.6^{\mathrm{a}}$ \\
\hline
\end{tabular}

extracts was found to be significantly higher than that of the stem $(16.21 \pm 0.46 \mathrm{GAE} / \mathrm{g}$, Table 2$)$. A similar result was observed when the flavonoid contents were compared between the stem and fruits; the stem showed a significantly higher flavonoid contents than the fruits (Table 2).

\section{DPPH antioxidant activity}

Two major antioxidant mechanisms, hydrogen atom transfer (HAT) and single electron transfer (SET), were classified. Thus HAT involves the transfer of hydrogen from the antioxidant compound to the free radical, which eventually neutralizes the free radical, as in the DPPH assay. Antioxidant potential of the control and the samples were significantly different. The extracts of leaf showed a significantly higher percentage of inhibition $(78.7 \pm 1.6)$ than the stem $(56.3 \pm 0.9)$ and fruit $(33.0 \pm 1.1)$, whereas the extracts of stem showed a significantly higher percentage of inhibition than fruit extract (Table 3). This trend seems in a good agreement with the data of TFC (Table 2), where the highest content was found in leaf extracts. This result clearly shows that the highest rate of DPPH decay occurs within the first $30 \mathrm{~min}$ of the reaction.

\section{Ferric-reducing antioxidant power assay}

The SET involves the transfer of an electron from the antioxidant compound, as in the FRAP assay. The samples reduce ferricyanide complex into ferrous $\left(\mathrm{Fe}^{2+}\right)$ form. The FRAP value of $540 \pm 52(\mathrm{mM}$ $\mathrm{Fe}(\mathrm{II}) / \mathrm{g}$ ) in stem extract was significantly higher than that of the leaf and fruit (Table 4). In addition, the FRAP value in the extracts of the leaf was found to be significantly higher than that of the fruit 
Table 4 Ferric-reducing antioxidant power value in different parts of $S$. torvum plants.

\begin{tabular}{lc}
\hline Samples & FRAP value $(\mathrm{mM} \mathrm{Fe}(\mathrm{II}) / \mathrm{g})$ \\
\hline Fruit & $112 \pm 11^{\mathrm{c}}$ \\
Stem & $540 \pm 52^{\mathrm{a}}$ \\
Leaf & $438 \pm 12^{\mathrm{b}}$ \\
\hline
\end{tabular}

extract (Table 4). A different trend was found in the ranking of DPPH and FRAP data: as for the FRAP data, the ranking results were in good agreement with the Total Phenols Index (Table 2), where the highest value was found for stem extracts. The extracts from fruits showed the lowest value in all assays, i.e., TPC, TFC, DPPH, and FRAP.

\section{DISCUSSION}

In the present work, the plant material was ovendried before the extractions. It is possible then that drying resulted in lower phenolic content in the fruits. In other studies with fresh fruits, it was found that phenolic compounds were higher in the fruits than in the stems ${ }^{25}$. Moreover, the phenol content could be higher in fresh than in thermally treated (such as oven-dried) plant materials ${ }^{25}$. In this particular case, the drying of stems, where the phenols are often present in the form of polymers of the lignin, should make them more easily extractable in oven-dried material, where the linked phenols become free by the action of temperature.

\section{Total phenolic content and total flavonoid content}

Phenolic compounds are one of the most important classes of secondary metabolites, mostly found in plants with diverse structures ${ }^{26}$. Phenolic compounds are among the greatest electron donors that can secure the conversion of $\mathrm{H}_{2} \mathrm{O}_{2}$ into $\mathrm{H}_{2} \mathrm{O}$ in a short period. Hence they are referred to as the powerful chain-breaking antioxidants ${ }^{27}$. The phenolic content from this experiment was found to be higher in the stem extracts compared to the leaf and fruit extracts. However, the leaf extracts revealed higher phenolic content than the fruit extracts. This differs from a study ${ }^{28}$ reporting a decreasing level of phenolic compound in the order of leaf $>$ fruit $>$ stem in $S$. nigrum plants.

The result of the current experiment contradicts the finding of a study ${ }^{29}$ reporting high phenolic content in the ethanolic fruit extract than the current experiment. Nevertheless, they reported lower amount of phenolic compounds from the ethanolic and the fruit methanolic extract than the current experiment ${ }^{2}$. However, Loganayaki et al ${ }^{11}$ reported high phenolic values than the current study from a chloroform fruit extract. Nonetheless, fruit acetone and methanol extracts were found to have lower phenolic values than our observed values. The current research found higher phenolic content in the leaf extracts than that reported in the previous study ${ }^{11}$. The differences may be attributed to the solvent used for extraction, environmental factors, fresh or dry samples, and the standard compounds used.

\section{Flavonoid contents}

Flavonoid compounds are naturally occurring compounds having a polyphenolic structure. They are mostly soluble in water and are ubiquitous in nature. However, they mainly occur in a plant as sugar derivatives known as glycosides. Nearest all pigments that colour most flowers, fruits, and seeds are due to the presence of flavonoids ${ }^{30}$. The result of flavonoid content revealed that leaves have high flavonoid content followed by stems. The fruit contains very low amount of TFC compared to that of leaves and stem. This corresponds with a report showing decrease in flavonoid content in the order leaf $>$ stem $>$ fruit in $S$. nigrum ${ }^{28}$. High flavonoid contents might be related to the high chlorophyll content $^{19}$ and different phytochemical compounds present in leaves ${ }^{30}$. Waghulde et $\mathrm{al}^{2}$ reported a low amount of flavonoid content in ethanolic, and fruit methanolic extract than the current experiment. This difference may be due to environmental factors, dry or fresh sample, standard compounds used and solvent used for extraction among others.

\section{DPPH assay}

The most rapid, reliable and sensitive method for measuring antioxidants of plant samples is free radical scavenging assay which measures the absorbance of DPPH stable radical spectrophotometrically $^{2}$. This slightly agreed with the report showing highest DPPH antioxidants from leaf followed by fruit and lastly stem extract of $S$. nigrum ${ }^{28}$. However, Waghulde et $\mathrm{al}^{2}$ reported that the percentagescavenging activity of ethanolic and methanolic fruit extract was higher than our observed result. However, the result of Ref. 12 from the different solvent of $S$. torvum fruits at $500 \mu \mathrm{g} / \mathrm{ml}$ revealed higher scavenging activity than the current research. Samrot et $\mathrm{al}^{29}$ reported a low percentage of DPPH scavenging activity of $S$. torvum leaves than in the current research. This difference may be attributed 
to the differences in solvent polarity, concentrations, and environmental factors.

\section{FRAP assay}

The reducing of the power of food constituents or bioactive compounds is an indicator of its electron donation potential and its antioxidant activity ${ }^{26}$. The FRAP value of leaf extract from the current experiment was found to be higher than the reported value of from both acetone and methanolic extracts ${ }^{9}$, while lower than the chloroform extract. Furthermore, previous study ${ }^{23}$ revealed low FRAP value from both raw and processed $S$. torvum fruit extracts. However, the FRAP value of fruit extract from the current experiment was significantly lower than the reported value from both acetone, methanolic and chloroform extracts ${ }^{11}$. Nevertheless, a low amount of FRAP value was found from different extracts of $S$. torvum leaf ${ }^{22}$ in comparison with the current research. This difference may be related to the differences in solvent polarity, concentration and environmental factors.

In conclusion, many studies focus on natural antioxidants from fruit, vegetables and medicinal plants. It may be related to high prevalence of oxidative diseases as well as the lethal effect of some synthetic antioxidants. It can be concluded that both DPPH and FRAP assays gave different results when the antioxidant activity was measured in stems and leaves of $S$. torvum, with corresponding responses in the fruit extracts where the lowest indexes were found.

Acknowledgements: The author would like to acknowledge Kano state government of Nigeria for the scholarship award and FRGS funding (FRGS/2/2014/STWN03/ UNISZA/02/1, Jahan MS) Sultan Zainal Abidin University, Malaysia for the research funding.

\section{REFERENCES}

1. Yousaf Z, Wang Y, Baydoun E (2013) Phytochemistry and pharmacological studies on Solanum torvum Swartz. J Appl Pharmaceut Sci 3(4), 152-60.

2. Waghulde H, Kamble S, Patankar P, Jaiswal B, Pattanayak S, Bhagat C, Mohan M (2011) Antioxidant activity, phenol and flavonoid contents of seeds of Punica granatum (Punicaceae) and Solanum torvum (Solanaceae). Pharmacologyonline 1, 193-202.

3. Ndebia EJ, Kamgang R, Nkeh-ChungagAnye BN (2006) Analgesic and anti-imflammatory properties of aqueous extract from leaves of Solanum torvum (Solanaceae). Afr J Tradit Complement Altern Med 4, 240-4.
4. Arthan D, Svasti J, Kittakoop P, Pittayakhachonwut D, Tanticharoen M, Thebtaranonth Y (2002) Antiviral isoflavonoid sulfate and steroidal glycosides from the fruits of Solanum torvum. Phytochemistry 59, 459-63.

5. Mahmood U, Shukla YN, Thakur RS (1983) Nonalkaloidal constituents from Solanum torvum leaves. Phytochemistry 22, 167-9.

6. Sivapriya M, Leela S (2007) Isolation and purification of a novel antioxidant protein from the water extract of Sundakai (Solanum torvum) seeds. Food Chem 104, 510-7.

7. Chah KF, Muko KN, Oboegbulem SI (2000) Antimicrobial activity of methanolic extract of Solanum torvum fruit. Fitoterapia 71, 187-9.

8. Lalitha V, Raveesha KA, Kiran B (2010) Antimicrobial activity of Solanum torvum Swart. against important seed borne pathogens of paddy. Iran J Energ Environ 1, 160-4.

9. Nguelefack TB, Mekhfi H, Dimo T, Afkir S, Nguelefack-Mbuyo EP, Legssyer A, Ziyyat A (2008) Cardiovascular and anti-platelet aggregation activities of extracts from Solanum torvum (Solanaceae) fruits in rat. J Compl Integr Med 5, 24-9.

10. Mohan M, Bhagat SJ, Sanjay K (2009) Effect of Solanum torvum on blood pressure and metabolic alterations in fructose hypertensive rats. $J$ Ethnopharmacol 126, 86-9.

11. Loganayaki N, Siddhuraju P, Manian S (2010) Antioxidant activity of two traditional Indian vegetables: Solanum nigrum L. and Solanum torvum L. Food Sci Biotechnol 19, 121-7.

12. Ramamurthy $\mathrm{CH}$, Kumar MS, Suyavaran VSA, Mareeswaran R, Thirunavukkarasu C (2012) Evaluation of antioxidant, radical scavenging activity and polyphenolics profile in Solanum torvum L. Fruits. J Food Sci 77, 907-13.

13. Boonchum W, Peerapornpisal Y, Kanjanapothi D, Pekkoh J, Pumas C, Jamjai U, et al (2011) Antioxidant activity of some seaweed from the gulf of Thailand. Int J Agr Biol 13, 95-9.

14. Gandhiappan J, Rengasamy R (2012) Comparative study on antioxidant activity of different species of Solanaceae family. Adv Appl Sci Res 3, 1538-44.

15. Luqman S, Srivastava S, Kumar R, Maurya AK, Chanda D (2012) Experimental assessment of Moringa oleifera leaf and fruit for its antistress, antioxidant, and scavenging potential using in vitro and in vivo assays. Evid Based Complement Altern Med 2012, 1-12.

16. Singleton VL, Orthofer R, Lamuela-Raventós RM (1999) [14] Analysis of total phenols and other oxidation substrates and antioxidants by means of Folin-Ciocalteu reagent. In: Oxidants and Antioxidants Part A, Methods in Enzymology vol 299, Elsevier, pp 152-78.

17. Vinson JA, Zubik L, Bose P, Samman N, Proch J 
(2005) Dried fruits: excellent in vitro and in vivo antioxidants. $J$ Am Coll Nutr 24, 44-50.

18. Ainsworth EA, Gillespie KM (2007) Estimation of total phenolic content and other oxidation substrates in plant tissues using Folin-Ciocalteu reagent. Nat Protocol 2, 875-7.

19. Abdulkadir AR, Jahan MS, Zawawi DD (2015) Effect of chlorophyll content and maturity on total phenolic, total flavonoid contents and antioxidant activity of Moringa oleifera leaf (Miracle tree). J Chem Pharmaceut Res 7, 1147-52.

20. Kalita P, Barman Tapan K, Pal Tapas K, Kalita R (2013) Estimation of total flavonoids content (TFC) and antioxidant activities of methanolic whole plant extract of Biophytum sensitivum Linn. J Drug Deliv Therapeut 3(4), 33-7.

21. Abdulkadir AR, Zawawi DD, Jahan MS (2015) DPPH antioxidant activity, total phenolic and total flavonoid content of different part of Drumstic tree (Moringa oleifera Lam.). J Chem Pharmaceut Res 7, 1423-8.

22. Clarke G, Ting KN, Wiart C, Fry J (2013) High correlation of 2,2-diphenyl-1-picrylhydrazyl (DPPH) radical scavenging, ferric reducing activity potential and total phenolics content indicates redundancy in use of all three assays to screen for antioxidant activity of extracts of plants from the Malaysian rainforest. Antioxidants 2, 1-10.

23. Abdulkadir AR, Zawawi DD, Yunusa AK, Jahan MS (2015) In vitro anti-oxidant potential, total phenolic content and total flavonoid content of methanolic flower and seed extract of miracle tree (Moringa Oleifera Lam.). Aust J Basic Appl Sci 9, 27-31.

24. Benzie IF, Strain JJ (1996) The ferric reducing ability of plasma (FRAP) as a measure of antioxidant power: the FRAP assay. Anal Biochem 239, 70-6.

25. Lutz M, Hernández J, Henríquez C (2015) Phenolic content and antioxidant capacity in fresh and dry fruits and vegetables grown in Chile. CyTA J Food 13, 541-7.

26. Cheynier V (2012) Phenolic compounds: from plants to foods. Phytochemistry Rev 11, 153-77.

27. Bendary E, Francis RR, Ali HMG, Sarwat MI, El Hady S (2013) Antioxidant and structure-activity relationships (SARs) of some phenolic and anilines compounds. Ann Agr Sci 58, 173-81.

28. Alam MN, Roy S, Anisuzzaman SM, Rafiquzzaman M (2012) Antioxidant activity of the ethanolic extracts of leaves, stems and fruits of Solanum nigrum. Pharmacogn Comm 2, 67-71.

29. Samrot AV, Mathew AA, Shylee L, Hemalatha N, Karunya A (2009) Evaluation of bioactivity of various Indian medicinal plants-an in-vitro study. Internet $J$ Intern Med 8, [online].

30. Abdulkadir AR, Zawawi DD, Jahan MS (2016) Proximate and phytochemical screening of different parts of Moringa oleifera. Russ Agr Sci 42, 34-6. 